\title{
A Simplified and Structured Teaching Tool for the Evaluation and Management of Pulseless Electrical Activity
}

\author{
Laszlo Littmann $^{\mathrm{a}}$ Devin J. Bustin ${ }^{\mathrm{b}}$ Michael W. Haley ${ }^{\mathrm{a}, \mathrm{c}}$ \\ Departments of ${ }^{\mathrm{a}}$ Internal Medicine and ${ }^{\mathrm{b}}$ Emergency Medicine, and ${ }^{\mathrm{C}}$ Pulmonary and Critical Care Consultants, \\ Carolinas Medical Center, Charlotte, N.C., USA
}

\section{Key Words}

Pulseless electrical activity - Cardiopulmonary resuscitation . Electrocardiogram $\cdot$ Echocardiogram

\begin{abstract}
Cardiac arrest victims who present with pulseless electrical activity (PEA) usually have a grave prognosis. Several conditions, however, have cause-specific treatments which, if applied immediately, can lead to quick and sustained recovery. Current teaching focuses on recollection of numerous conditions that start with the letters $\mathrm{H}$ or $\mathrm{T}$ as potential causes of PEA. This teaching method is too complex, difficult to recall during resuscitation, and does not provide guidance to the most effective initial interventions. This review proposes a structured algorithm that is based on the differentiation of the PEA rhythm into narrow- or wide-complex subcategories, which simplifies the working differential and initial treatment approach. This, in conjunction with bedside ultrasound, can quickly point towards the most likely cause of PEA and thus guide resuscitation.

(c) 2013 S. Karger AG, Basel
\end{abstract}

\section{Introduction}

Patients with pulseless electrical activity (PEA) account for up to $30 \%$ of cardiac arrest victims $[1,2]$. The survival rate of patients with PEA is much worse than that of cardiac arrest patients with shockable rhythms $[1,3]$. Studies suggest that cause-specific treatment of PEA is more effective than general treatments offered by advanced cardiac life support (ACLS) guidelines such as cardiac massage, epinephrine and vasopressin [4]. Higher-dose epinephrine has actually been shown to be associated with worse outcomes [5]. Both the European and American ACLS guidelines, therefore, stress the significance of quickly finding and addressing the cause of PEA $[6,7]$. Memory aids list numerous conditions whose English names start with the letters $\mathrm{H}$ or $\mathrm{T}$ as potentially treatable causes of PEA (fig. 1) [6, 7]. Studies, however, have shown that during cardiopulmonary resuscitation it is difficult to recall up to 13 causes of PEA [8]. Moreover, even if such a list can be generated, the ACLS does not provide guidance on the relative likelihood of the specific causes, nor does it offer suggestions on how to individualize treatments based on simple initial findings.

These limitations of current ACLS guidelines have been recognized and attempts have been made to sim-

\begin{tabular}{|c|c|}
\hline KARGER & $\begin{array}{ll}\text { (๑) 2013 S. Karger AG, Basel } & \text { Karger } \\
1011-7571 / 14 / 0231-0001 \$ 39.50 / 0 & \text { Open access }\end{array}$ \\
\hline $\begin{array}{l}\text { E-Mail karger@karger.com } \\
\text { www.karger.com/mpp }\end{array}$ & $\begin{array}{l}\text { This is an Open Access article licensed under the terms of the } \\
\text { Creative Commons Attribution-NonCommercial 3.0 Un- } \\
\text { ported license (CC BY-NC) (www.karger.com/OA-license), } \\
\text { applicable to the online version of the article only. Distribu- } \\
\text { tion permitted for non-commercial purposes only. }\end{array}$ \\
\hline
\end{tabular}

Laszlo Littmann, $\mathrm{MD}, \mathrm{PhD}$

Department of Internal Medicine

Carolinas Medical Center

P.O. Box 32861, Charlotte, NC 28232 (USA)

E-Mail Laszlo.Littmann@ carolinashealthcare.org 


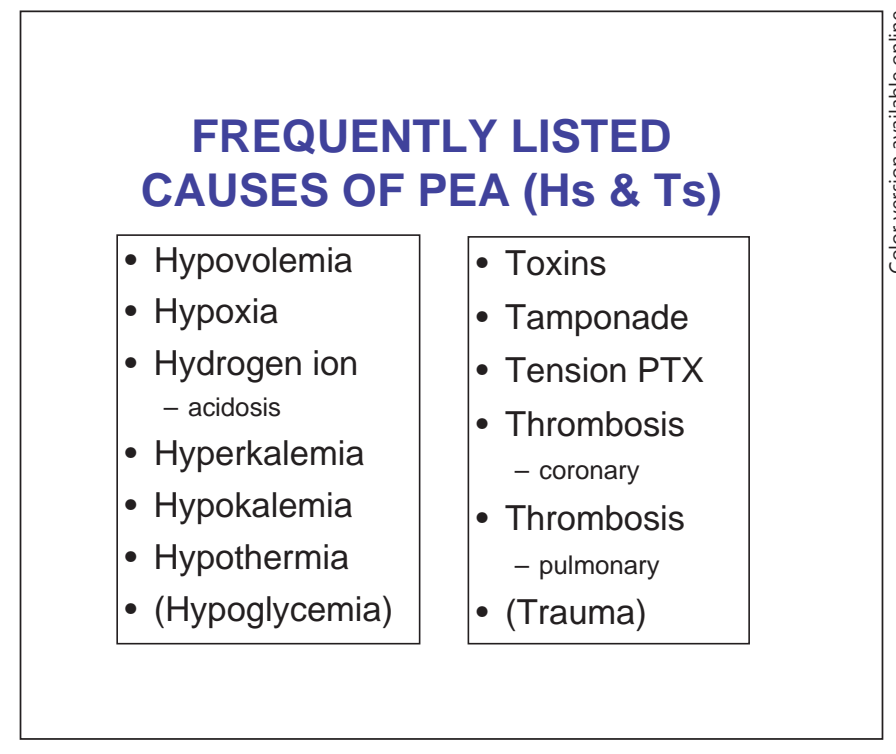

Fig. 1. Causes of PEA listed by European and American guidelines. Hypoglycemia and trauma have been removed from the most recent ACLS guidelines [6, 7]. PTX = Pneumothorax.

plify the evaluation of patients who present with cardiac arrest due to PEA $[9,10]$. There were also attempts to use the electrocardiogram (ECG) and bedside echocardiogram to guide the diagnosis and management of PEA [10-16]. Over the last few years we have developed a teaching tool that simplifies the diagnostic approach by differentiating narrow- and wide-complex rhythms on initial telemetry ( $Q R S$ duration $<0.12$ and $\geq 0.12 \mathrm{~s}$, respectively), and by eliminating those diagnoses which rarely if ever cause PEA. Our algorithm does not apply in the specific trauma setting. This algorithm has not been systematically tested but is supported by scientific and clinical principles and by a thorough review of the literature.

\section{The New PEA Algorithm: Diagnostic Aspects}

The multiple Hs and Ts that are frequently quoted as possible causes of PEA are listed in figure 1. It seems obvious that recollection of these can be near impossible in the acute setting. Our simplified algorithm that focuses on differentiation between narrow or wide QRS complexes is shown in figure 2. This should be an easy distinction that can be discerned by simply looking at the telemetry monitor during resuscitation. The general assumption is that narrow-complex PEA is generally due to a mechanical problem frequently caused by right ventricular inflow or outflow obstruction, whereas wide-complex PEA is typically due to a metabolic problem or ischemia and left ventricular failure. Wide-complex PEA may also indicate agonal rhythm.

The four most common mechanical causes of PEA arrest include cardiac tamponade, tension pneumothorax, mechanical hyperinflation and pulmonary embolism (fig. 2). The clinical scenario can usually help navigate between these causes. Jugular venous distension and muffled heart sounds suggest tamponade. Rib fracture, severe emphysema, positive pressure ventilation and hyperexpanded chest indicate pneumothorax, mechanical hyperinflation or auto-PEEP $[17,18]$. Cancer history and deep venous thrombosis suggest pulmonary embolism. In all of these cases cardiac ultrasound usually shows preserved or even hyperdynamic left ventricular function indicative of pseudo-PEA (fig. 2) [10-14]. A collapsed right ventricle suggests inflow obstruction from tamponade, pneumothorax or hyperinflation. A dilated right ventricle, on the other hand, indicates possible pulmonary embolism. Thoracic ultrasonography may also help in direct pleural assessment and in the diagnosis of pneumothorax.

Wide-complex PEA usually suggests a metabolic problem such as severe hyperkalemia with or without metabolic acidosis, or sodium channel blocker toxicity (fig. 2) $[19,20]$. Again, the clinical scenario is usually helpful: in 


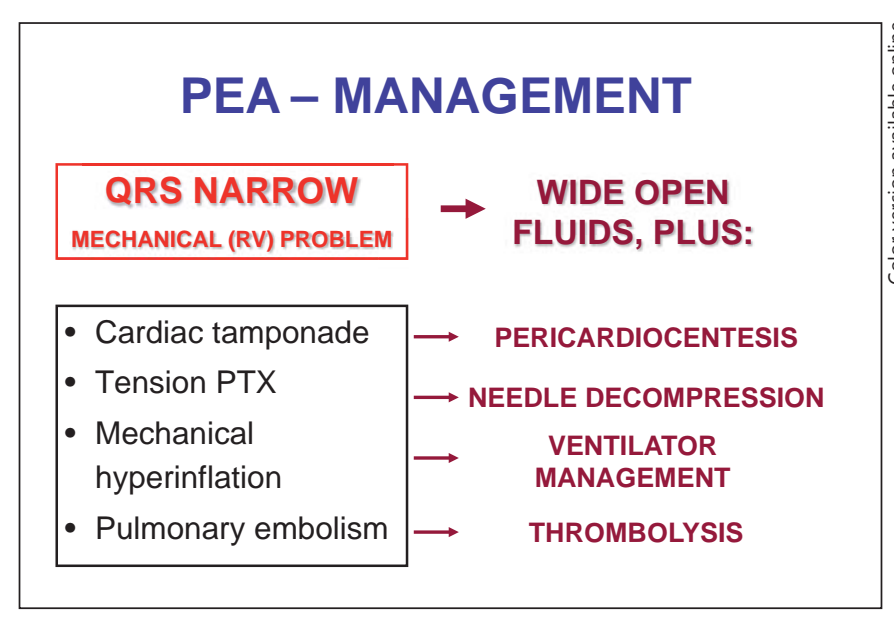

Fig. 3. Treatment recommendations for narrow-complex PEA. PTX = Pneumothorax: RV = right ventricular.

patients with critical illness, sepsis, shock or renal failure, the diagnosis of wide-complex PEA is usually hyperkalemia. Identification of an arteriovenous fistula or dialysis catheter also suggests hyperkalemia. In patients who were 'found down' or who present following ingestion or suicide attempt, the cause of wide-complex PEA is almost always sodium channel blocker toxicity [21]. In widecomplex PEA, a metabolic or ischemic cause is supported by the echocardiographic observation of left ventricular hypokinesis or standstill (fig. 2). Other possible causes of wide-complex PEA include a mechanical etiology with preexisting aberrancy or pulmonary embolism - a mechanical cause that can be associated with complete right bundle branch block. In these cases too, bedside ultrasound can quickly point to a mechanical cause.

Patients with acute myocardial infarction (MI) can also present with PEA. Patients who undergo prehospital resuscitation for MI and PEA typically have a dismal prognosis, despite aggressive management including thrombolytics [22, 23]. In hospitalized patients with acute MI, PEA is usually a relatively late manifestation. Here too, the ECG is crucial in distinguishing a mechanical cause such as myocardial rupture from pump failure [24, 25]. The former is usually associated with narrow QRS complexes, whereas the latter is associated with widened QRS complexes (fig. 2). Immediate recognition of possible myocardial rupture can be life-saving as with emergent surgical intervention some patients may survive for decades [25]. Wide-complex PEA associated with acute MI or with other agonal rhythms, on the other hand, has dismal prognosis with no effective treatments.

A Simplified Teaching Tool for PEA

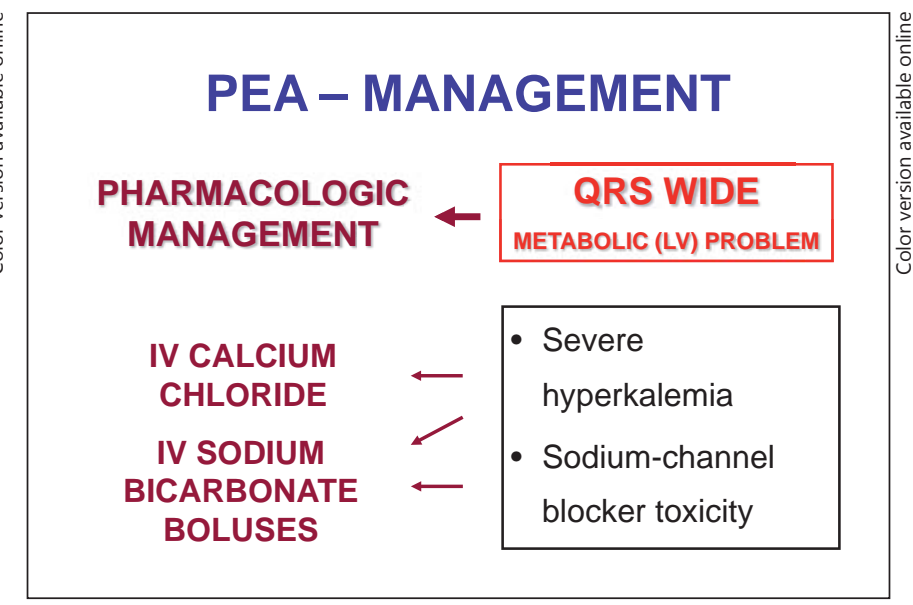

Fig. 4. Treatment recommendations for wide-complex PEA. IV = Intravenous; LV = left ventricular.

An important question is whether this simplified algorithm covers all important causes of PEA? We believe that it does. A recent thorough review of the PEA literature by Desbiens [9] and our independent review did not find any evidence that hypoxemia, hypokalemia or hypoglycemia presents primarily with PEA. Hypothermia is not listed in our new algorithm, but there the clinical picture is usually quite obvious. Of 'toxins', the initial presentation of $\beta$-blocker, calcium channel blocker and digitalis toxicity is almost always hypotension, sinus bradycardia, sinus arrest or atrioventricular block [26, 27]. Some of these do progress to PEA but by that time the diagnosis is usually well established [28-30]. Standard treatments are available for these conditions [26, 31]. Of the other possible 'Ts', we have excluded trauma, as have the newest guidelines $[6,7]$, because traumatic arrests have unique management strategies separate from current ACLS guidelines [32], and signs are usually apparent on exam.

\section{The New PEA Algorithm: Therapeutic Considerations}

How this simplified and structured approach to PEA can guide initial treatment is shown in figures 3 and 4 . For patients with narrow-complex PEA from a suspected mechanical etiology, aggressive intravenous fluid administration should be initiated as these causes are potentially fluid responsive. After that, based on the most likely clinical scenario or results of bedside ultrasonog- 
raphy, pericardiocentesis, needle decompression, adjustment of ventilation or thrombolytic therapy should be considered (fig. 3). For wide-complex PEA intravenous calcium chloride and sodium bicarbonate should be administered if the clinical picture indicates hyperkalemia. Intravenous sodium bicarbonate boluses should be given if the clinical picture suggests sodium channel blocker toxicity (fig. 4) [33]. Neither calcium nor bicarbonate is likely to have any effect on narrow-complex PEA.

\section{Discussion}

There is considerable debate surrounding the most appropriate approach to cardiac arrest due to PEA [412]. Our simplified and structured approach offers three new elements compared to official European and American guidelines. First, rather than randomly listing 10 13 causes of PEA with terms starting with the letters $\mathrm{H}$ or $\mathrm{T}$, our algorithm categorizes the possible causes based on the easy finding of QRS complexes being narrow or wide in a simple telemetry or rhythm strip (fig. 2). Narrow-complex PEA is usually due to a mechanical cause, whereas wide-complex PEA is usually due to a metabolic cause. Second, within each category we have markedly reduced the number of listings to those diagnoses that have the highest likelihood and clinical relevance. Among the mechanical causes we have listed cardiac tamponade, tension pneumothorax, mechanical hyperinflation and pulmonary embolism. The clinical scenario and, if available, bedside ultrasonography should quickly distinguish among these. When the presentation is wide-complex PEA or nonshockable pulseless widecomplex tachycardia, the most likely causes include severe hyperkalemia or sodium channel blocker toxicity. Metabolic acidosis without hyperkalemia is usually the consequence rather than the cause of PEA. Third, our algorithm provides specific treatment recommendations that are based on the initial QRS morphology on telemetry (fig. 3, 4). In narrow-complex PEA, wide-open fluids should be started. It is important to remember that the problem is frequently right ventricular inflow obstruction where overzealous mechanical ventilation and vigorous external cardiac compression may actually be harmful $[18,34]$. Consideration should be given to perform immediate needle decompression or pericardiocentesis, or to administer thrombolytic therapy. The use of intravenous calcium or sodium bicarbonate as initial management should be discouraged, and the use of epi- nephrine should be limited. Several studies have shown that routine, indiscriminate use of these agents is ineffective or harmful in PEA [5, 35-38]. With wide-complex PEA or nonshockable pulseless wide-complex tachycardia, the initial treatment of choice is intravenous calcium and/or sodium bicarbonate $[6,7,33]$. Needle decompression, pericardiocentesis and thrombolytic administration should be entertained only if a mechanical cause is suggested by history or bedside ultrasound.

There is strong physiological basis behind these recommendations. In PEA the heart usually produces some mechanical action but it generates such a low blood pressure that it does not result in a palpable pulse [39]. The main mechanisms of PEA include mechanical obstruction to right ventricular filling or outflow, or severe pump failure. The mechanical causes are not directly related to abnormal myocardial performance (pseudo-PEA) and therefore are almost always associated with narrow QRS complexes. Pump failure resulting in PEA, on the other hand, is usually due to blockade of the cardiac sodium channels either directly by sodium channel blocker toxicity or by extracellular hyperkalemia [40]. Severe ischemia may also be associated with potassium accumulation and reduced sodium transport $[41,42]$. At the cellular level sodium channel blockade causes flattening of phase zero of the cardiac action potential; in the surface ECG this is reflected by widening of the QRS complexes [43]. Decreased sodium influx results in diminished release of calcium from the sarcoplasmic reticulum and reduced activation of the tropomyosin complex [44]. In both hyperkalemia and sodium channel blocker toxicity, therefore, the width of the QRS complex is a good indicator of clinical severity [19-21].

\section{Limitations}

Whereas a presentation with narrow-complex PEA almost always indicates a mechanical cause, mechanical causes can occasionally present with wide QRS complexes. Examples include patients with preexisting bundle branch blocks, cases of massive pulmonary embolism causing right bundle branch block, and the rare combination of acute MI - new left bundle branch block and myocardial rupture. Following a prolonged downtime or prolonged resuscitation all mechanical causes of PEA may eventually result in wide QRS complexes but by that time the rhythm is typically agonal with minimal or no chance of survival.

Our new algorithm has not been systematically tested for inclusiveness or resuscitation outcome. Of note, neither the American or European ACLS guidelines nor
Littmann/Bustin/Haley 
any of the newer proposals have ever been tested in the clinical setting $[6,7,9-14]$. It may actually be quite difficult to perform a randomized trial comparing the new algorithm with the official ACLS guidelines because instruction on the new algorithm can introduce bias. A more realistic approach would be to systematically teach the new algorithm to all house staff within an institution and then collect outcome data of consecutive cases of resuscitation for PEA and compare those with historic data.

\section{Conclusion}

Using the presenting ECG from a simple telemetry recording can quickly direct evaluation of PEA towards the most likely etiology. Narrow-complex PEA usually signifies pseudo-PEA that is due to a mechanical cause. If confirmed by bedside ultrasound, treatment can be directed at relieving the mechanical obstruction. Wide-complex PEA suggests a metabolic cause; early administration of intravenous calcium or sodium bicarbonate may be lifesaving.

\section{References}

1 Engdahl J, Bång A, Lindqvist J, et al: Factors affecting short- and long-term prognosis among 1,069 patients with out-of-hospital cardiac arrest and pulseless electrical activity. Resuscitation 2001;51:17-25.

2 Cobb LA, Fahrenbruch CE, Olsufka M, et al: Changing incidence of out-of-hospital ventricular fibrillation, 1980-2000. JAMA 2002; 288:3008-3013.

-3 Nadkarni VM, Larkin GL, Peberdy MA, et al: First documented rhythm and clinical outcome from in-hospital cardiac arrest among children and adults. JAMA 2006;295:50-57.

$\checkmark 4$ Saarinen S, Nurmi J, Toivio T, et al: Does appropriate treatment of the primary underlying cause of PEA during resuscitation improve patients' survival? Resuscitation 2012; 83:819-822.

5 Arrich J, Sterz F, Herkner H, et al: Total epinephrine dose during asystole and pulseless electrical activity cardiac arrest is associated with unfavourable functional outcome and increased in-hospital mortality. Resuscitation 2012;83:333-337.

6 Deakin CD, Nolan JP, Soar J, et al: European Resuscitation Council Guidelines for Resuscitation 2010 Section 4. Adult advanced life support. Resuscitation 2010;81:1305-1352.

7 Neumar RW, Otto CW, Link MS, et al: Part 8: adult advanced cardiovascular life support: 2010 American Heart Association Guidelines for Cardiopulmonary Resuscitation and Emergency Cardiovascular Care. Circulation 2010;122:S729-S767.

8 Morgan R, Westmoreland C: Survey of junior hospital doctors' attitudes to cardiopulmonary resuscitation. Postgrad Med J 2002;78: 413-415.

9 Desbiens NA: Simplifying the diagnosis and management of pulseless electrical activity in adults: a qualitative review. Crit Care Med 2008;36:391-396.
10 Hernandez C, Shuler K, Hannan $\mathrm{H}$, et al: CAUSE: cardiac arrest ultra-sound exam - a better approach to managing patients in primary non-arrhythmogenic cardiac arrest. Resuscitation 2008;76:198-206.

11 Querellou E, Leyral J, Brun C, et al: In and out-of-hospital cardiac arrest and echocardiography: a review. Ann Fr Anesth Reanim 2009;28:769-778.

12 Labovitz AJ, Noble VE, Bierig M, et al: Focused cardiac ultrasound in the emergent setting: a consensus statement of the American Society of Echocardiography and American College of Emergency Physicians. J Am Soc Echocardiogr 2010;23:1225-1230.

13 Testa A, Cibinel GA, Portale G, et al: The proposal of an integrated ultrasonographic approach into ALS algorithm for cardiac arrest: the PEA protocol. Eur Rev Med Pharmacol Sci 2010;14:77-88.

14 Lanctôt JF, Valois M, Beaulieu Y: EGLS: echoguided life support. Crit Ultrasound J 2011;3: 123-129.

15 Aufderheide TP, Thakur RK, Stueven HA, et al: Electrocardiographic characteristics in EMD. Resuscitation 1989;17:183-193.

16 Mehta C, Brady W: Pulseless electrical activity in cardiac arrest: electrocardiographic presentations and management considerations based on the electrocardiogram. Am J Emerg Med 2012;30:236-239.

17 Lapinsky SE, Leung RS: Auto-PEEP and electromechanical dissociation. N Engl J Med 1996;335:674.

18 Conacher ID: Dynamic hyperinflation - the anaesthetist applying a tourniquet to the right heart. Br J Anaesth 1998;81:116-117.

19 Delk C, Holstege CP, Brady WJ: Electrocardiographic abnormalities associated with poisoning. Am J Emerg Med 2007;25:672-687.

20 Littmann L, Monroe MH, Taylor L III, et al: The hyperkalemic Brugada sign. J Electrocardiol 2007;40:53-59.

21 Harrigan RA, Brady WJ: ECG abnormalities in tricyclic antidepressant ingestion. Am J Emerg Med 1999;17:387-393.
22 McNally B, Robb R, Mehta M, et al: Out-ofhospital cardiac arrest surveillance: Cardiac Arrest Registry to Enhance Survival (CARES), United States, October 1, 2005 - December 31, 2010. MMWR Surveill Summ 2011;60:119.

23 Koeth O, Nibbe L, Arntz HR, et al: Fate of patients with prehospital resuscitation for STelevation myocardial infarction and a high rate of early reperfusion therapy (results from PREMIR, Prehospital Myocardial Infarction Registry). Am J Cardiol 2012;109:1733-1737.

24 López-Sendón J, González A, López de Sá E, et al: Diagnosis of subacute ventricular wall rupture after acute myocardial infarction: sensitivity and specificity of clinical, hemodynamic and echocardiographic criteria. J Am Coll Cardiol 1992;19:1145-1153.

25 Pink E, Foot CL, Garlick B, et al: Survival following ventricular free wall rupture: a case series. Crit Care Resusc 2006;8:43-45.

26 DeWitt CR, Waksman JC: Pharmacology, pathophysiology and management of calcium channel blocker and $\beta$-blocker toxicity. Toxicol Rev 2004;23:223-238.

27 Ramoska EA, Spiller HA, Winter M, et al: A one-year evaluation of calcium channel blocker overdoses: toxicity and treatment. Ann Emerg Med 1993;22:196-200.

28 Hendren WG, Schieber RS, Garrettson LK: Extracorporeal bypass for the treatment of verapamil poisoning. Ann Emerg Med 1989; 18:984-987.

29 Pertoldi F, D’Orlando L, Mercante WP: Electromechanical dissociation $48 \mathrm{~h}$ after atenolol overdose: usefulness of calcium chloride. Ann Emerg Med 1998;31:777-781.

30 Behringer W, Sterz F, Domanovits $\mathrm{H}$, et al: Percutaneous cardiopulmonary bypass for therapy resistant cardiac arrest from digoxin overdose. Resuscitation 1998;37:47-50.

31 Kerns W II: Management of $\beta$-adrenergic blocker and calcium channel antagonist toxicity. Emerg Med Clin North Am 2007;25: 309-331. 
32 Kortbeek JB, Al Turki SA, Ali J, et al: Advanced trauma life support, 8 th edition, the evidence for change. J Trauma 2008;64:16381650.

33 Kolecki PF, Curry SC: Poisoning by sodium channel blocking agents. Crit Care Clin 1997; 13:829-848.

34 Hogan TS: External cardiac compression may be harmful in some scenarios of pulseless electrical activity. Med Hypotheses 2012;79: 445-447.

35 Spöhr F, Wenzel V, Böttiger BW: Drug treatment and thrombolytics during cardiopulmonary resuscitation. Curr Opin Anaesthesiol 2006;19:157-165.
36 Williamson K, Breed M, Alibertis K, et al: The impact of the code drugs: cardioactive medications in cardiac arrest resuscitation. Emerg Med Clin North Am 2012;30:65-75.

37 Stueven HA, Thompson B, Aprahamian C, et al: The effectiveness of calcium chloride in refractory electromechanical dissociation. Ann Emerg Med 1985;14:626-629.

38 Väyrynen T, Kuisma M, Määttä T, et al: Who survives from out-of-hospital pulseless electrical activity? Resuscitation 2008;76:207213.

39 Paradis NA, Martin GB, Goetting MG, et al: Aortic pressure during human cardiac arrest: identification of pseudo-electromechanical dissociation. Chest 1992;101:123-128.

40 Ballantyne F III, Davis LD, Reynolds EW Jr: Cellular basis for reversal of hyperkalemic electrocardiographic changes by sodium. Am J Physiol 1975;229:935-940.
41 Kléber AG: Resting membrane potential, extracellular potassium activity, and intracellular sodium activity during acute global ischemia in isolated perfused guinea pig hearts. Circ Res 1983;52:442-450.

42 Carmeliet E: Cardiac ionic currents and acute ischemia: from channels to arrhythmias. Physiol Rev 1999;79:917-1017.

43 Shinozaki T, Satoh S, Miura M, et al: The rise time of the monophasic action potential: a new index of local use-dependent conductivity by sodium channel blockers in human myocardium. Jpn Circ J 1997;61:979-987.

44 Bers DM: Cardiac excitation-contraction coupling. Nature 2002;415:198-205. 